\title{
Post-traumatic intracranial pseudo-aneurysms of posterior circulation: a comprehensive review of an under-diagnosed and rare entity
}

\author{
Mauro Palmieri ${ }^{1}$ - Alessandro Pesce ${ }^{2}$. Giuseppa Zancana ${ }^{1} \cdot$ Daniele Armocida $^{1}$ - Aniello Maiese ${ }^{3} \cdot$ Carlo Cirelli $^{4}$. \\ Antonio Santoro ${ }^{1} \cdot$ Paola Frati ${ }^{3} \cdot$ Vittorio Fineschi ${ }^{3} \cdot$ Alessandro Frati $^{1,5}$
}

Received: 5 July 2021 / Revised: 8 September 2021 / Accepted: 23 September 2021 / Published online: 4 October 2021

(c) The Author(s) 2021, corrected publication 2021

\begin{abstract}
Traumatic aneurysms are rare and the total number of cases involving the posterior circulation (TIPC) is even smaller. Traumatic brain injury (TBI) may be responsible not only of rupture in brain aneurysm (BrA) pre-existing to trauma, but it has been identified also as a possible pathogenetic cause of TIPC formation in patients not affected by intracranial vascular lesions. A complete literature review was performed of all reported cases regarding rupture of BrA with SAH resulting from TIPC not previously identified at the first radiological screening. A representative case of a left posterior inferior cerebellar artery (PICA) pseudo-aneurysm caused by left vertebral artery's dissection is reported. We show a unique complete collection of all 34 cases. Despite their rarity, TIPCs are associated with a significant morbidity and mortality rate, as high as $40-60 \%$. Of the 22 patients with good neurological status (64.7\%), we did not notice a significant correlation with regard to the location of the aneurysm, type of treatment, or clinical onset. Early recognition of a pseudo-aneurysm and adequate treatment seem to be the most important prognostic factor for these patients. Despite their rarity, TIPCs are associated with a significant morbidity and mortality rate. A TIPC should be suspected in case of delayed deterioration in head-injured patient and should be investigated with angiography. Conservative management is worsened by poor prognosis and the goal of treatment is to exclude the aneurysm from circulation with surgical or endovascular methods as soon as possible.
\end{abstract}

Keywords Post-traumatic brain aneurysms $\cdot$ Intracranial aneurysms $\cdot$ Brain trauma $\cdot$ Vascular lesions $\cdot$ Complications

\section{Introduction}

Brain aneurysms $(\mathrm{BrA})$ represent the most common intracranial vascular condition, with an incidence of 1-2\% [33]. $\mathrm{BrA}$ that develops following head injuries presents a rare

Mauro Palmieri

Mauro.palmieri10@gmail.com

1 Human Neuroscience Department - Neurosurgery Division "Sapienza" University, Roma, Italy

2 Santa Maria Goretti Hospital, Neurosurgery Division, Latina, Italy

3 Department of Anatomical, Histological, Forensic and Orthopaedic Sciences SAIMLAL - "Sapienza" University, Rome, Italy

4 Department of Radiological, Oncological and Anatomopathological Sciences, Unit of Interventional Neuroradiology, "Sapienza" University of Rome, Umberto I University Hospital, Rome, Italy

5 IRCCS “Neuromed”, Pozzilli, IS, Italy and unique challenge both during the diagnostic and surgical treatment phases [17, 40]. Traumatic intracranial aneurysms are rare, comprising $1 \%$ or less of all cerebral aneurysms and the total number of cases involving the posterior circulation is even smaller.

A spontaneous rupture of $\mathrm{BrA}$ addresses for the $80 \%$ of non-traumatic cases of subarachnoid hemorrhage $(\mathrm{SAH})$ [18] with a reported case fatality rate that ranges between 25 and $50 \%$ (where several risk factors have been identified in high blood pressure, kidney disorders, alcohol consumption, and arterial walls' infections [13, 34]). BrA rupture resulting from traumatic brain injury (TBI) represents a well-note but less common occurrence [13]. TBI may be responsible not only for rupture in $\mathrm{BrA}$ pre-existing to trauma, but it has also been identified as a possible pathogenetic cause of pseudoaneurysms' formation in patients not affected by intracranial vascular lesions before the traumatic event, where this occurrence is less common in the posterior intracranial circulation. Traumatic intracranial pseudo-aneurysm of the posterior circulation (TIPC) is most frequently reported in 
the first three decades of life. TIPCs have been reported in association with both closed and penetrating trauma [44, 47]; even though it is described as a rare occurrence, the formation of these particular types of pseudo-aneurysms that the dissection of cervical arteries might cause [28] is due to high-speed TBI [10].

There are quite a few case reports on this topic; however, larger studies, let alone prospective studies, are lacking, so the real incidence is not known, what are the risk factors, and why they are entities so complicated to diagnose compared to their supratentorial counterparts.

In the present paper, a complete literature review was performed of all reported cases in which a rupture of $\mathrm{BrA}$ with SAH results from TIPC was not previously identified at the first radiological screening. Also, we report a representative case from our department experience of a left posterior inferior cerebellar artery (PICA) pseudo-aneurysm caused by the left vertebral artery's dissection.

\section{Material and methods}

The study was conducted following preferred reporting items for systematic reviews.

The English literature was systematically investigated using MEDLINE, the NIH Library, PubMed, and Google Scholar. The last search date was June 15, 2021.

Search terms included: "post-traumatic" or "traumatic" in combination with "intracranial" or "brain aneurysm." Searches were limited to human studies and no limits regarding language, and we excluded a period of publication before 1978. Backward citation tracking was applied to identify articles not retrieved by electronic searches.

We have fully focused our attention on TIPC as it is less common and described in reported cases of post-traumatic aneurysms and because, we believe, they are more subtle from the point of view of symptom onset and diagnostic imaging.

\section{Selection criteria}

Two independent authors conducted the selection of abstracts for full review based on predefined inclusion and exclusion criteria. Studies were eligible if they reported original data on the case of posterior post-traumatic BrA. Studies excluded were as follows: (a) papers regarding aneurysm located in other locations than the posterior circulation; (b) case report related to penetrating traumas or with (c) with incomplete data; (d) paper presenting a re-analysis of subpopulations already included in other studies; were commentaries or review articles summarizing the results of the previous series; (e) year of publishing was also included to understand a possible year of experience/improvement of the technologic setup, and (f) the articles do not report or specify the diagnostic and therapeutic measures adopted.

Each author reviewed the abstracts independently and generated a list of studies to retrieve for full-text review (Fig. 1).

\section{Representative case}

A 26-year-old male with a negative medical history was led to the Emergency Department because of a progressively worsening state of consciousness after severe physical aggression with concomitant TBI and consequent fall to the ground with further brain injury. At admission, blood analysis showed strong positivity for cannabinoids and alcohol. The neurological onset measured with the Glasgow coma scale (GCS) at admission was 8 . Therefore, a brain computed tomography (CT) was performed, and it disclosed the presence of a subarachnoid hemorrhage (SAH) located in Sylvian, prepontine, premedullary, and interpeduncular cisterns bilaterally with diffuse intraventricular hemorrhage (Fisher 4). A brain angio-CT scan was immediately performed, which did not disclose the presence of vascular lesions in cervical and intracranial arteries (Fig. 1). A bilateral frontoparietal decompressive craniectomy was performed with concomitant positioning of an external ventricular drainage. After the surgical intervention, the patient was moved to the intensive care unit (ICU). After $24 \mathrm{~h}$, a brain CT was performed, which showed a reduction of cerebral edema, absence of hydrocephalus, and SAH volume stability. Pharmacological sedation was suspended on the seventh post-operative day.

Nine days after the trauma, the patient suddenly became unresponsive, the GCS dropped to 3, and a brain CT was performed immediately, highlighting an increased volume of the SAH volume in the peribulbar cistern the hemorrhage in the third and fourth ventricles (Fig. 1). Therefore, a brain angio-CT was performed, which showed massive vasospasm of all intracranial arteries and ectasia of the left V4 tract of vertebral artery of $11 \mathrm{~mm}$ with stenosis of the cranial segments of the artery, the origin of the left postero-inferior cerebellar artery (PICA), and the V4 tract of the right vertebral artery (VA). Moreover, a sacciform aneurysmal dilation with a maximum dimension of $3.6 \times 4.5 \mathrm{~mm}$ at the origin of the left PICA was highlighted, with anterolateral projection and signs of sac's rupture (Fig. 2). Consequentially, a DSA was performed, which confirmed the diffused arterial vasospasm, the presence of the aneurysm, and the ectasia of V4 due to dissection of the vertebral artery (Fig. 2). Since decompressive craniectomy has been performed already and given the good functioning of the external ventricular drainage, the 
Fig. 1 A Axial and $\mathbf{B}$ sagittal scans o the first angio-CT and the same scans in $\mathbf{C}$ and D 9 days after the trauma. The arrows highlight the site of the left PICA where the post-traumatic aneurysm has formed

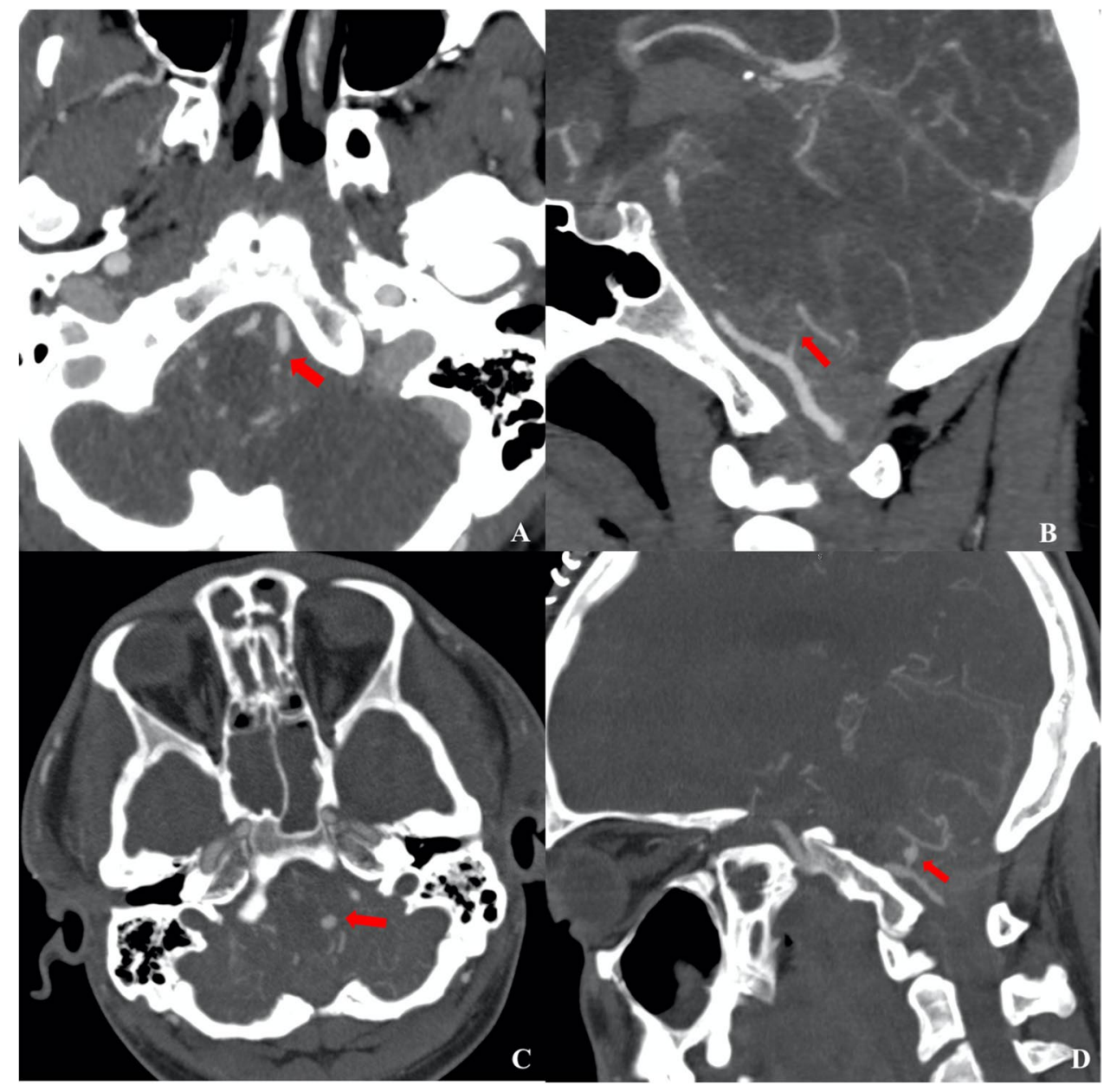

Fig. 2 DSA frames showing the presence of the post-traumatic aneurysm and the concomitant presence of left V4 tract of the vertebral artery wall's dissection
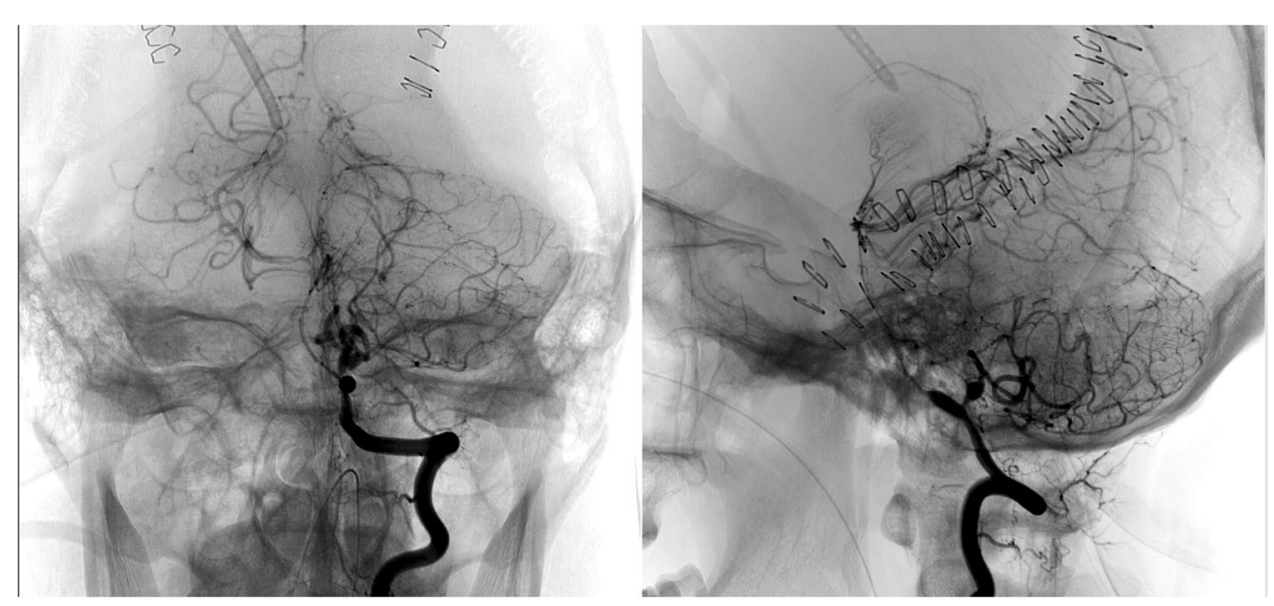

diffuse cerebral vasospasm, and the critical clinical and neurological conditions, no surgical or endovascular procedures were proposed. After this episode, the patient's hospitalization continued in ICU.

In the following days, brain CT and a brain MRA were performed, which showed the unchanged dimension of both
PICA aneurysm and V4 dissection, confirmed by a cerebral DSA executed after 1 month.

In the following 3 months, the radiological follow-up showed the consequences of diffuse cerebral ischemia; hence, no modifications of the aneurysmal dilation were highlighted (Fig. 3) until a selective DSA for the study 
of the left PICA was performed. The exam, performed 4 months after the sudden post-operative neurological worsening, showed an increase of the aneurysm's dimension, from $3.6 \times 4.5 \mathrm{~mm}$ to $9.0 \mathrm{~mm}$. Therefore, endovascular embolization of the left $\mathrm{V} 4$ tract of the left vertebral artery was performed through coiling (Fig. 3). One month later, the patient died due to sudden respiratory insufficiency.

\section{Results}

The main search returned a total of 831 papers, including a total of 477 patients. To this initial cohort, the exclusion, as mentioned earlier, criteria were applied, accordingly eliminating 801 papers for a total of 33 patients. To this cohort of patients, the personal experience of a unique case of posttraumatic $\mathrm{BrA}$ was added.

A data extraction sheet was designed to extract all the necessary information visible in Table 1 . The data were subsequently verified between the two authors. The following details were extracted: authors and year of publication, sex, age, type of trauma, neurological status expressed as GCS, reported onset symptoms, intracranial pathological signs reported at first CT-scan, symptoms occurred during the observation phase for which the patient performed a second CT control, the result of first DSA, the time occurred to the first diagnosis of pseudo-aneurysm, localization, type of treatment and outcome.

The patients in total, including our representative case, are 34 (27 males and 7 females), with an average age of 25.67. The most common traumatic cause reported concerns about vehicle accidents (29.4\%), assaults (29.4\%), and accidental falls (26.4\%).
Patients at the time of the first neurologic evaluation most frequently have severe neurological status with 12 patients in a coma (35.3\%) and in $47 \%$ of cases GCS less than 8 .

However, we found wide variability in the presentation of the initial symptoms, also highlighting asymptomatic patients with accidental or mild headache (26.47\%).

As can be seen from the table, in no case is the presence of aneurysm reported at the first CT scan radiological control time. Of all the cases analyzed, no patient underwent intracranial DSA at admission to the emergency unit.

Patients repeated a new radiological control as a follow up (in 55.9\%) or at the onset of new neurological disorders (44.1\%). The in-depth diagnostic study with DSA occurred in 16 patients $(47.05 \%)$ of cases with time elapsed from the traumatic event varying between $24 \mathrm{~h}$ and 5 months. Notably, only in 8 patients of our collection, the pseudoaneurysmatic formation was present at the time of the first angiographic control.

Once the pseudo-aneurysmatic formation with a new DSA was identified, the most common location was the PICA in 12/34 patients (35.3\%), followed by the location in the basilar artery (BA) and VA in 20.5\% (7 BA and 7 VA cases), superior cerebellar artery (SCA, 6 cases, 17.6\%), and posterior cerebral artery (PCA, 2 cases, $5.9 \%$ ) respectively. The treatment choice is also highly variable in this case, with 16 patients treated by endovascular route $(47 \%)$ and 10 treated with a surgical procedure $(29.4 \%)$. We find only one reported case treated with a combined endovascular and neurosurgical approach. On 3 reports, the procedure is not reported, while for 4 patients, the choice for conservative treatment is reported for clinical severity or spontaneous and complete thrombosis (2 patients, $5.88 \%$ of cases).

Despite their rarity, according to literature, TIPCs are associated with a significant morbidity and mortality rate, as high as $40-60 \%$ [44.47]. As an outcome measure, we
Fig. 3 DSA frames showing the result of the embolization of the left vertebral artery, carried out 3 months after the trauma

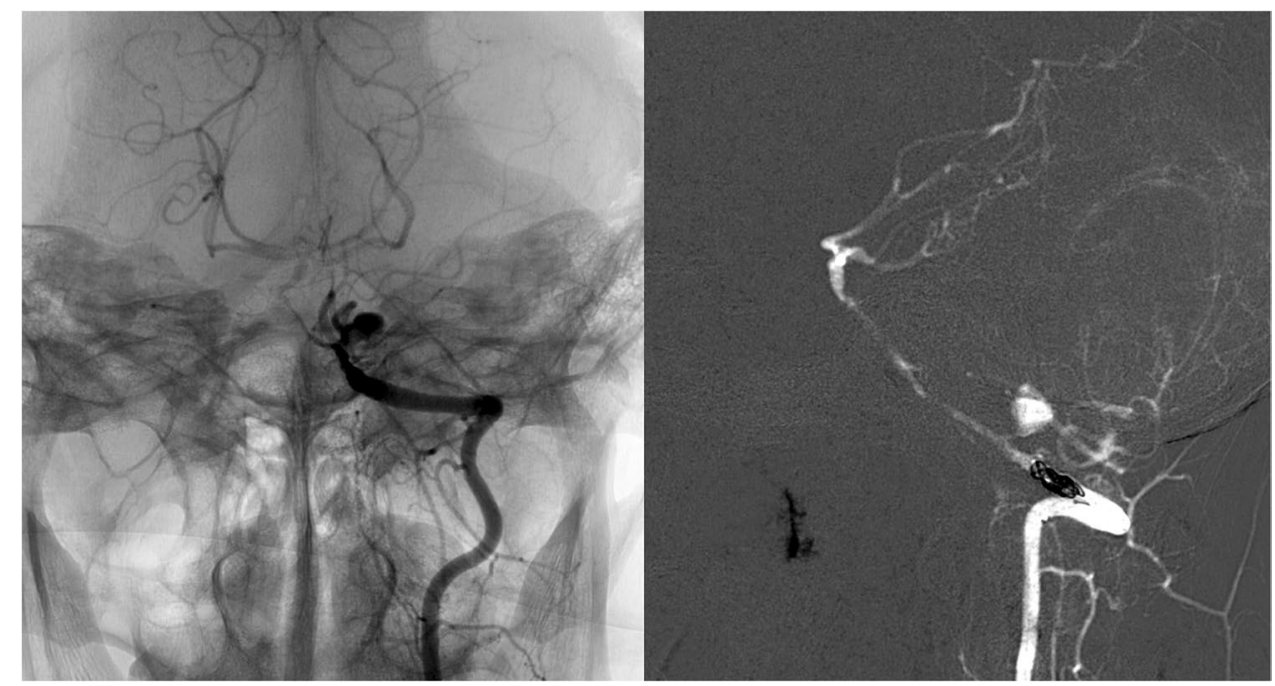




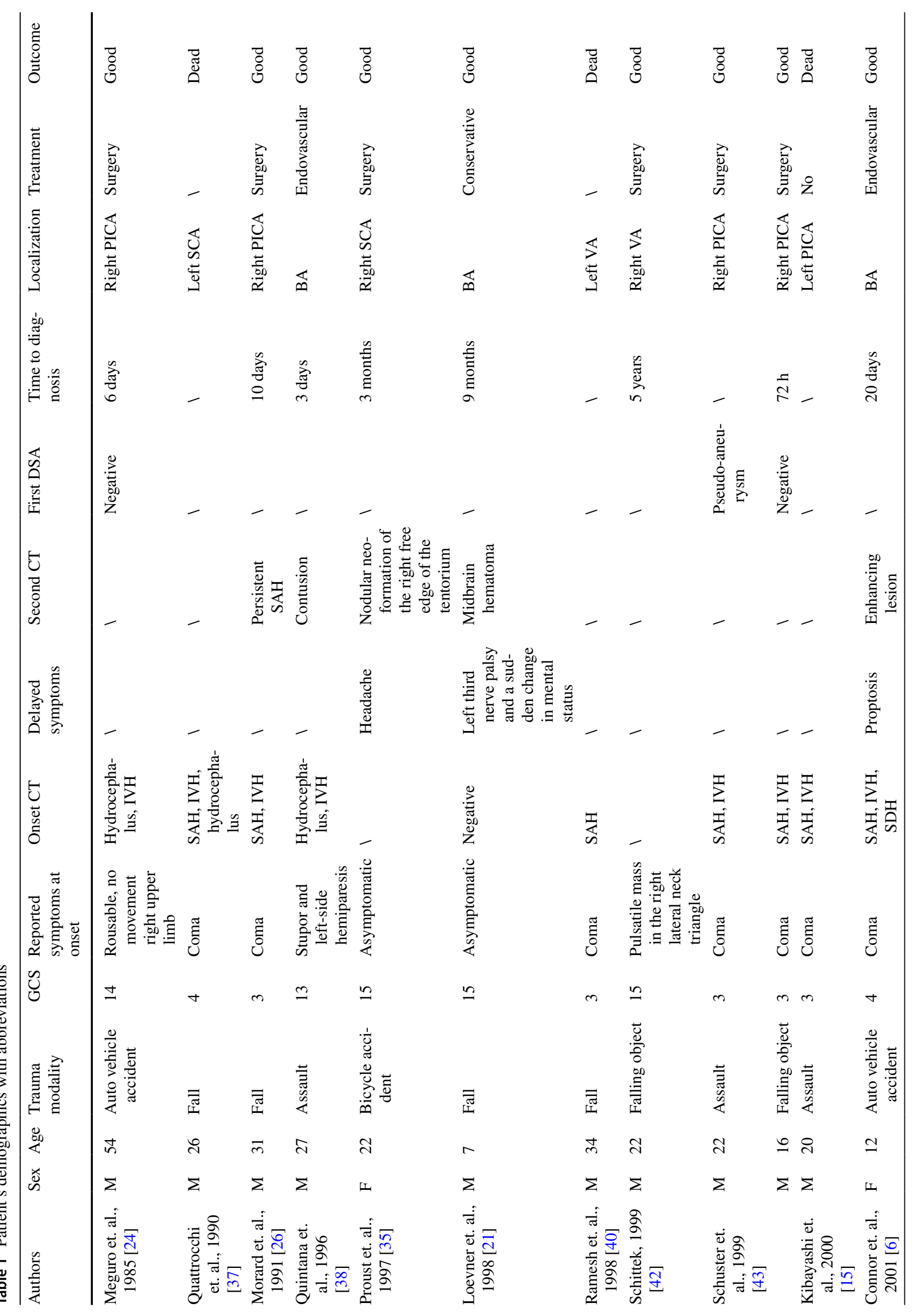




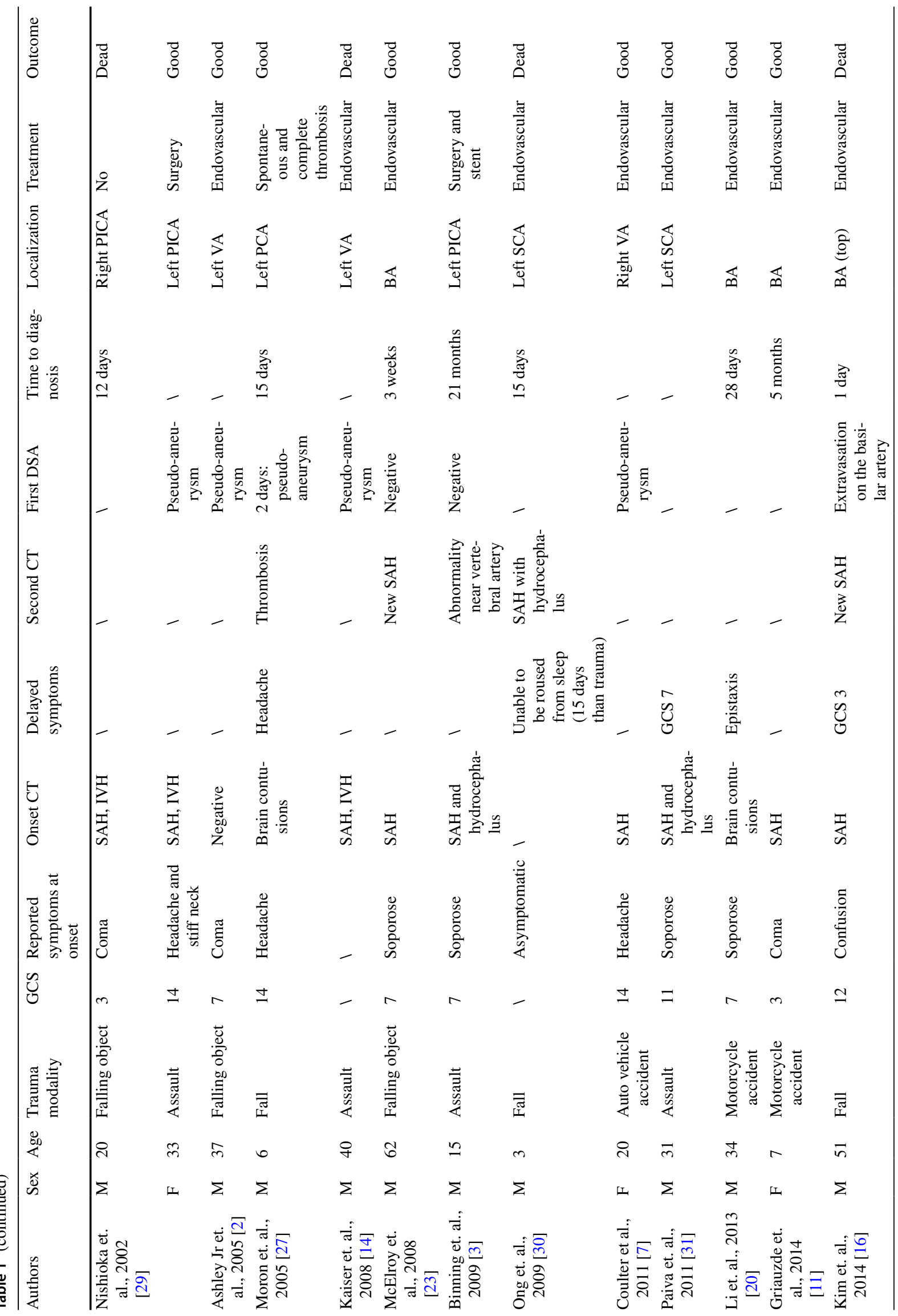




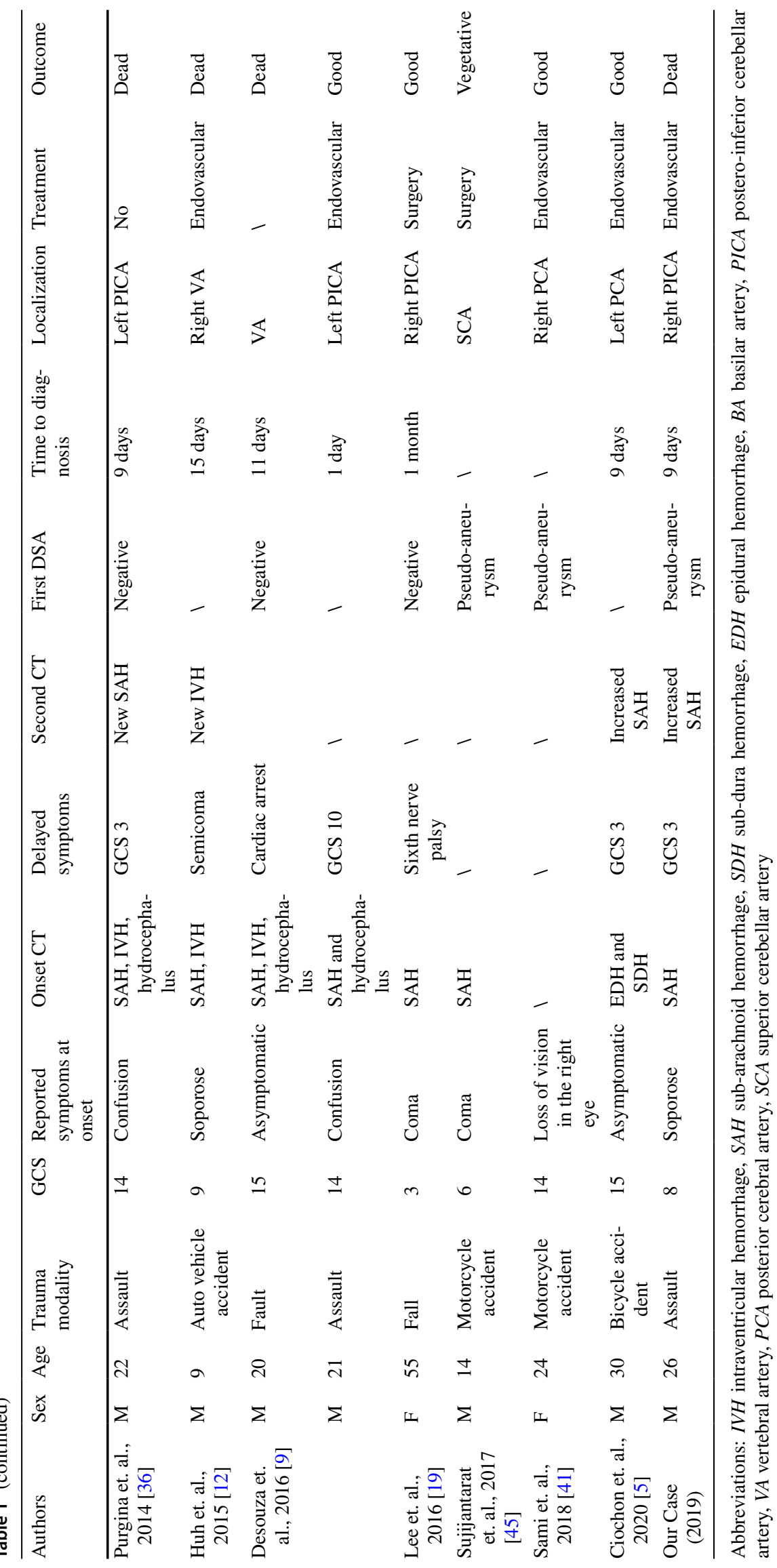


identified as GOOD status patients discharged with an undamaged neurological examination or with mild disorders that did not impact their performance status. Of the 22 patients with good neurological status (64.7\%), we did not notice a significant correlation between the aneurysm location, type of treatment, or clinical onset. However, early recognition of a pseudo-aneurysm and adequate treatment seem to be the most important prognostic factor for this particular category of patients where the small collection does not allow for more in-depth statistical evaluations.

A TIPC should be suspected in case of delayed deterioration in a head-injured patient and should be investigated with angiography $[1,4,5,22,25,44,47]$. Conservative management is worsened by poor prognosis $[25,28,34]$.

\section{Discussion}

The post-traumatic BrA represents a rare condition, with a reported incidence that ranges from $3.2-3.6 \%$ to $5.7 \%$, and they account for less than $1 \%$ of all $\mathrm{BrA}$ [25]. According to histological features, post-traumatic aneurysms are classified in [8]:

True aneurysms: the lesion affects tunica intima of the arterial wall, with variable initial involvement of the internal elastic lamina and tunica media, while tunica externa is preserved. This condition weakens the different layers of the vessel's wall, creating intraluminal hemodynamic changes that determine the formation of the aneurysm, with the possibility of partial rupture and consequent repair.

False aneurysms (or pseudo-aneurysms): they are generally associated with penetrant traumas, which causes transmural lesions of the arterial wall and consequent formation of an extra-parietal hematoma. The bleeding caused by the rupture of these types of BrA starts immediately after the trauma and the risk of second bleeding is extremely high since it may occur even after the resolution of surrounding hematoma and cerebral edema [36]. Mixed aneurysms: these are real $\mathrm{BrA}$ that, due to the formation of a transmural hematoma after rupture, develop a false lumen.

Post-traumatic BrA is most commonly located in the anterior circulation, even though seldom cases of lesions located in correspondence of VA and BAs have been reported [17]. This particular kind of BrA usually forms near fractures or where the artery is closely connected to the dura mater [38]. Moreover, when an extracranial artery enters the dura, the external elastic lamina disappears; hence, the arterial wall is weaker and more susceptible to rupture [39].
PICA aneurysms are rare, with a general incidence of $2.8 \%$ [32], but if we consider only the series of PITC, they become the most frequent site, and they are most commonly located at the origin of the artery. Saccular aneurysms are usually located at the distal portion of the artery, while BrA originating from dissection are encountered in the proximal tract, associated with parent vessel's ectasia and concurrent distal or proximal stenosis [46], exactly like the case described in the present paper.

Since cases of SAH following post-traumatic BrAs' rupture located in the posterior circulation are rare, only seldom reports can be found in current Literature (Table 1). Shuster et al. [43] reported 3 cases of post-traumatic SAH, 2 of those related to the posterior tract of the PICA, which occurred shortly after closed-head TBI, suggesting that even moderate traumas can cause rupture of PICA aneurysms. According to these authors, this might be related to particular anatomical variants of PICA and predisposing vascular disease [43]. Moreover, they suggest that the presence of persistent hydrocephalus and symptomatic vasospasm in their cases is evidence that corroborates the traumatic etiopathogenesis of the rupture since these particular clinical features are reported in only the 5-12\% of spontaneous ruptures of PICA's aneurysms [43]. Nishioka et al. [29] reported 2 analog cases, proposing the brainstem's sudden movement on the sagittal plane with acceleration-deceleration of the cerebellum as the possible pathogenetic cause of the rupture. Further evidence is retrieved from the case of a young male involved in a scuffle [15], in which it is suggested that the PICA's rupture might be caused by the transitory occlusion of the homolateral vertebral artery due to rotatory movements of the neck that may be associated to a blood flow inversion from the basilar artery to the occluded vertebral artery, causing PICA's rupture at its origin.

Even though that the only possible way to exclude the pre-existence of the aneurysm would have been to perform a radiological exam before the trauma, the negativity for vascular lesion highlighted by the brain CTA at admission suggests that the first SAH was probably due to dissecting damage of left vertebral artery caused by the trauma. Moreover, the entity of the physical aggression and the consequent further brain injury and the positivity for cannabinoids and alcohol could explain the severity of the neurological state at admission. This particular lesion led to the formation of the PICA's aneurysm, which dimensions progressively grew in the days following the trauma, along with the increase of entity of the dissection located at the V4 tract of the left vertebral artery.

Most aneurysms manifest angiographically in 2-3 weeks with an average of 20 days $[1,17,33]$ and often this examination is performed to investigate the reasons for an incomprehensible clinical worsening or for late post-hemorrhagic control, and these data are also confirmed to examine the 
pseudo-aneurysm of the posterior circulation. It is well known that arterial vasospasm can hide the eventual presence of $\mathrm{BrA}$ in the context of diffuse SAH [22]. However, an important consideration is relevant in this particular case: the brain CTA performed at admission did not show a suggestive presence of arterial vasospasm, while the CTA and, even more, the cerebral DSA executed when the post-operative neurological worsening occurred showed the existence of the aneurysm and the dissection of the vertebral artery despite the presence of severe cerebral vasospasm. This evidence supports the thesis that the aneurysm most probably was not formed before the trauma or, at least, its dimensions were not notable for being identified through radiological exams at admission.

Moreover, an important limitation given by the difficulty of understanding this high rate of misdiagnosis at the beginning of the pathological process of aneurysmal formation is that what kind of DSA was done is almost never reported (if images from 2 directions, images from 4 directions or 3D); however, the quality and techniques of DSA should be discussed, if an increase of angiograms is recommended.

So, the diagnosis of TIPC requires a high index of suspicion; anytime a head-injured patient presents a delayed neurological deterioration, it should be promptly submitted to cerebral DSA [47].

In conclusion, we affirm that a follow-up angiogram should be obtained even if the initial one was negative. The second DSA should be performed at least 3 weeks after the trauma, and it could be argued that a third angiogram should be performed 6-12 weeks after injury [4, 34, 47].

\section{Conclusions}

Despite their rarity, TIPCs are associated with a significant morbidity and mortality rate. A TIPC should be suspected in case of delayed deterioration in a head-injured patient with concomitant pronounced SAH and should be investigated with angiography after performing a brain CTA in first place. A poor prognosis worsens conservative management, and the goal of treatment is to exclude the aneurysm from circulation with surgical or endovascular methods as soon as possible.

Author contribution MP and AF proposed the present paper. MP, GZ, and DA conducted the literature review. AM, PF, and VF provided the case description and part of "Discussion" section. CC analyzed and prepared the radiological image. MP and AF analyzed the paper retrieved from literature review and wrote the "Discussion" section. Language editing was conducted by MP and VF. AP, AF, and AS supervised the literature review and revised the whole manuscript.
Funding Open access funding provided by Università degli Studi di Roma La Sapienza within the CRUI-CARE Agreement.

Data availability Not applicable.

Code availability Not applicable.

\section{Declarations}

Ethical approval All procedures performed in studies involving human participants were in accordance with the ethical standards of the institutional and/or national research committee and with the 1964 Helsinki declaration and its later amendments or comparable ethical standards.

This article does not contain any studies with animals performed by any of the authors.

Consent to participate All clinical and radiological information regarding the present article were collected and properly anonymized in full respect of current legislation in terms of privacy and consent to participation. All the relevant consents were collected.

Consent for publication All clinical and radiological information regarding the present article were collected and properly anonymized in full respect of current legislation in terms of privacy and consent for publication. All the relevant consents were collected.

Conflict of interest The authors declare no competing interests.

Open Access This article is licensed under a Creative Commons Attribution 4.0 International License, which permits use, sharing, adaptation, distribution and reproduction in any medium or format, as long as you give appropriate credit to the original author(s) and the source, provide a link to the Creative Commons licence, and indicate if changes were made. The images or other third party material in this article are included in the article's Creative Commons licence, unless indicated otherwise in a credit line to the material. If material is not included in the article's Creative Commons licence and your intended use is not permitted by statutory regulation or exceeds the permitted use, you will need to obtain permission directly from the copyright holder. To view a copy of this licence, visit http://creativecommons.org/licenses/by/4.0/.

\section{References}

1. Aarabi B (1995) Management of traumatic aneurysms caused by high-velocity missile head wounds. Neurosurg Clin N Am 6:775-797

2. Ashley WW Jr, Rivet D, Cross DWT III (2006) Development of a giant cervical vertebral artery pseudoaneurysm after a traumatic C1 fracture: case illustration. Surg Neurol 66:80-81

3. Binning MJ, Hauschild TB, Amini A, MacDonald JD (2009) Delayed post-traumatic saccular aneurysm of PICA in an adolescent. Acta Neurochir (Wien) 151(12):1647-1648. https://doi.org/ 10.1007/s00701-009-0323-4

4. Britz GW, Newell DW, West GA, Winn RH (2004) Traumatic cerebral aneurysms secondary to penetrating intracranial injuries. In: Winn Richard H. editor.th Youmans Neurological Surgery. 5 ed. Philadelphia: Saunders Edition; 2004

5. Ciochon UM, Steuble Brandt EG, Stavngaard T (2020) Acute tentorial subdural hematoma caused by rupture of the posterior 
cerebral artery after minor trauma-a case report. Diagnostics (Basel). 10(3):175. https://doi.org/10.3390/diagnostics10030175

6. Connor SEJ, Martin AJ, Deasy NP, Jeffree MA, Strong AJ (2001) Traumatic basilar pseudoaneurysm with a basilar-cavernous arteriovenous fistula. Neuroradiology 43:249-253

7. Coulter I, Shanmuganathan M, Fouyas I, Keston P (2011) A traumatic pseudoaneurysm of the vertebral artery. Br J Neurosurg 25(3):430-1

8. Debette S, Compter A, Labeyrie MA, Uyttenboogaart M, Metso TM, Majersik JJ et al (2015) Epidemiology, pathophysiology, diagnosis, and management of intracranial artery dissection. Lancet Neurol 14(6):640-654

9. deSouza RM, Shah M, Koumellis P, Foroughi M (2016) Subarachnoid haemorrhage secondary to traumatic intracranial aneurysm of the posterior cerebral circulation: case series and literature review. Acta Neurochir (Wien) 158(9):1731-40. https://doi.org/10.1007/ s00701-016-2865-6

10. Engelter ST et al (2017) Dissection of cervical and cerebral arteries. Curr Neurol Neurosci Rep 17:59

11. Griauzde J, Gemmete JJ, Chaudhary N, Pandey AS, Garton HJ (2014) Basilar artery pseudoaneurysm pre- senting at 5-month follow-up after traumatic atlanto-occipital dislocation in a 7-yearold girl treated with intracranial stent placement and coiling. J Neurointerv Surg 6:e8

12. Huh CW, Nam KH, Choi CH, Lee JI (2015) Post traumatic pseudoaneurysm arising from V4 segment of vertebral artery: a case report. Korean J Neurotrauma 11(2):154-7. https://doi.org/10. 13004/kjnt.2015.11.2.154

13. Juvela S, Hillbom M, Numminen H, Koskinen P (1993) Cigarette smoking and alcohol consumption as risk factors for aneurysmal subarachnoid hemorrhage. Stroke 24:639-646

14. Kaiser Ch, Schnabel A, Berkefeld J, Bratzke H (2008) Traumatic rupture of the intracranial vertebral artery due to rotational acceleration. Forensic Sci Int 182(1-3):e15-7. https://doi.org/10. 1016/j.forsciint.2008.10.001

15. Kibayashi $\mathrm{K}$ et al (2000) Traumatic basal subarachnoid hemorrhage due to rupture of the posterior inferior cerebellar arterycase report. Neurol Med Chir (Tokyo) 40(3):156-9

16. Kim BC, Lee JI, Cho WH, Nam KH (2014) Fatal traumatic subarachnoid hemorrhage due to acute rebleeding of a pseudoaneurysm arising from the distal basilar artery. J Korean Neurosurg Soc 56(5):428-30. https://doi.org/10.3340/jkns.2014.56.5.428

17. Larson PS, Reisner A, Morassutti DJ, Abdulhadi B, Harpring JE (2000) Traumatic intracranial aneurysms. Neurosurg Focus 8(1):e4. https://doi.org/10.3171/foc.2000.8.1.1829

18. Lawton MT, Vates GE (2017) Subarachnoid hemorrhage. N Engl J Med 377(3):257-266

19. Lee SH, Moon JU, Choi SK, Choi MK, Lee J, Sung JY (2016) Pseudoaneurysm at the distal posterior inferior cerebellar artery after blunt head trauma: a case report and review of the literature. World Neurosurg 92:580.e11-580.e15. https://doi.org/10.1016/j. wneu.2016.06.054

20. Li T, Zhang Y, Gu Z, Ma X, Yang X (2013) Traumatic pseudoaneurysm of the basilar artery presenting with fatal epistaxis: a rare case report. Brain Inj 27(11):1316-1319. https://doi.org/10.3109/ 02699052.2013.812242

21. Loevner LA, Ting TY, Hurst RW, Goldberg HI, Schut L (1998) Spontaneous thrombosis of a basilar artery traumatic aneurysm in a child. AJNR Am J Neuroradiol 19:386-388

22. Maher M, Schweizer TA, Macdonald RL (2020) Treatment of spontaneous subarachnoid hemorrhage: guidelines and gaps. Stroke 51(4):1326-1332

23. McElroy KM, Malone RJ, Freitag WB, Keller I, Shepard S, Roychowdhury S (2008) Traumatic pseudoaneurysm of the basilar artery. Am J Phys Med Rehabil 87:690-691
24. Meguro K, Rowed DW (1985) Traumatic aneurysm of the posterior inferior cerebellar artery caused by fracture of the clivus. Neurosurgery 16:666-668

25. Miley JT, Rodriguez GJ, Qureshi AI (2008) Traumatic intracranial aneurysm formation following closed head injury. J Vasc Interv Neurol 1(3):79-82

26. Morard M, de Tribolet N (1991) Traumatic aneurysm of the posterior inferior cerebellar artery: case report. Neurosurgery 29(3):438-41. https://doi.org/10.1097/00006123-19910 $9000-00018$

27. Morón F, Benndorf G, Akpek S, Dempsy R, Strother CM (2005) Spontaneous thrombosis of a traumatic posterior cerebral artery aneurysm in a child. AJNR Am J Neuroradiol 26(1):58-60

28. Nakstad P Hj et al (2008) Correlation of head trauma and traumatic aneurysms. Interv Neuroradiol 14(1):33-8

29. Nishioka T et al (2002) Unexpected delayed rupture of the vertebral - posterior inferior cerebellar artery aneurysms following closed head injury. Acta Neurochir (Wien) 144(8):839-45 (discussion 845)

30. Ong CK, Ong MT, Lam DV, Wenderoth JD (2010) Catastrophic delayed rupture of a traumatic aneurysm of the distal superior cerebellar artery in a child. J Clin Neurosci 17(4):515-7. https:// doi.org/10.1016/j.jocn.2009.06.041

31. Paiva WS, Andrade AF, Sterman Neto H, de Amorim RL, Caldas JG, Teixeira MJ (2012) Traumatic pseudoaneurysm of the superior cerebellar artery. J Trauma Acute Care Surg 72:E115

32. Peluso JP et al (2008) Posterior inferior cerebellar artery aneurysms: incidence, clinical presentation, and outcome of endovascular treatment. AJNR Am J Neuroradiol 29(1):86-90

33. Pesce A, Palmieri M, Zancana G, Salvati M, Santoro A, Raco A, Frati A (2020) Radiation-induced brain aneurysms: institutional experience and state of the art in the contemporary literature. World Neurosurg 135:339-351

34. Policicchio D, Muggianu G, Dipellegrini G, Boccaletti R (2018) Delayed diagnosis of post-traumatic aneurysm of distal anterior cerebral artery. Surg Neurol Int 9:222

35. Proust F, Callonec F, Bellow F et al (1997) Tentorial edge traumatic aneurysm of the superior cerebellar artery. J Neurosurg 87:950-954

36. Purgina B, Milroy M (2015) Fatal traumatic aneurysm of the posterior inferior cerebellar artery with delayed rupture. Forensic Sci Int 247:e1-5

37. Quattrocchi KB, Nielsen SL, Poirier V et al (1990) Traumatic aneurysm of the superior cerebellar artery: case report and review of the literature. Neurosurgery 27:476-479

38. Quintana F, Diez C, Gutierrez A, Diez ML, Austin O, Vazquez A (1996) Traumatic aneurysm of the basilar artery. AJNR Am J Neuroradiol 17(283-285): 19

39. Ritz K, Denswil NP, Stam OC, van Lieshout JJ, Daemen MJ (2014) Cause and mechanisms of intracranial atherosclerosis. Circulation 130(16):1407-14

40. Sahjpaul RL, Abdulhak MM, Drake CG, Hammond RR (1998) Fatal traumatic vertebral artery aneurysm rupture. Case report. J Neurosurg 89(5):822-4. https://doi.org/10.3171/jns.1998.89.5. 0822

41. Sami MT, Gattozzi DA, Soliman HM, Reeves AR, Moran CJ, Camarata PJ, Ebersole KC (2018) Use of Pipeline ${ }^{\mathrm{TM}}$ embolization device for the treatment of traumatic intracranial pseudoaneurysms: case series and review of cases from literature. Clin Neurol Neurosurg 169:154-160. https://doi.org/10.1016/j.clineuro.2018. 04.012

42. Schittek A (1999) Pseudoaneurysm of the vertebral artery. Tex Heart Inst J 26:90-95

43. Schuster JM, Santiago P, Elliott JP, Grady MS, Newell DW, Winn HR (1999) Acute traumatic posteroinferior cerebellar artery 
aneurysms: report of three cases. Neurosurgery 45(6):1465-7 (discussion 1467-8)

44. Shiue I, Arima H, Hankey GJ, Anderson CS, ACROSS Group (2012) Modifiable lifestyle behaviours account for most cases of subarachnoid haemorrhage: a population-based case-control study in Australasia. J Neurol Sci 313(1-2):92-4. https://doi.org/ 10.1016/j.jns.2011.09.017

45. Sujijantarat N, Pierson MJ, Kemp J, Coppens JR (2017) Staged trapping of traumatic basilar trunk pseudoaneurysm: case report and review of literature. World Neurosurg 108:991.e7-991.e12. https://doi.org/10.1016/j.wneu.2017.08.144
46. Taylor AG et al (2001) A dissecting aneurysm of the posterior inferior cerebellar artery. A case report. Interv Neuroradiol 7(3):253-7

47. Ventureyra EC, Higgins M (1994) Traumatic intracranial aneurysms in childhood and adolescence. Case reports and review of the literature. Childs Nerv Syst 10:361-793

Publisher's note Springer Nature remains neutral with regard to jurisdictional claims in published maps and institutional affiliations. 